\title{
Clickers or Flashcards: Is There Really a Difference?
}

N. Lasry, John Abbott College, Montreal Canada, and Harvard School of Engineering \& Applied Sciences, Cambridge MA

$\Lambda$ growing number of physics teachers are currently turning to instructional technologies such as wireless handheld response systems —colloquially called clickers. Two possible rationales may explain the growing interest in these devices. The first is the presumption that clickers are more effective instructional instruments. The second rationale is somewhat reminiscent of Martin Davis' declaration when purchasing the Oakland Athletics: "As men get older, the toys get more expensive." Although personally motivated by both of these rationales, the effectiveness of clickers over inexpensive low-tech flashcards remains questionable. Thus, the first half of this paper presents findings of a classroom study comparing the differences in student learning between a Peer Instruction group using clickers and a Peer Instruction group using flashcards. Having assessed student learning differences, the second half of the paper describes differences in teaching effectiveness between clickers and flashcards.

\section{About Peer Instruction}

Peer Instruction (PI) is a student-centered instructional approach developed at Harvard by Eric Mazur. ${ }^{1}$ The method has been welcomed by the science community and adopted by a large number of colleges and universities due, among other reasons, to its common sense approach and its documented effectiveness. ${ }^{1,2} \mathrm{~A}$ schematic description of the PI method used in this study is shown in Fig. 1.

In PI, the progression of any given class depends on the outcome of real-time student feedback to Con-

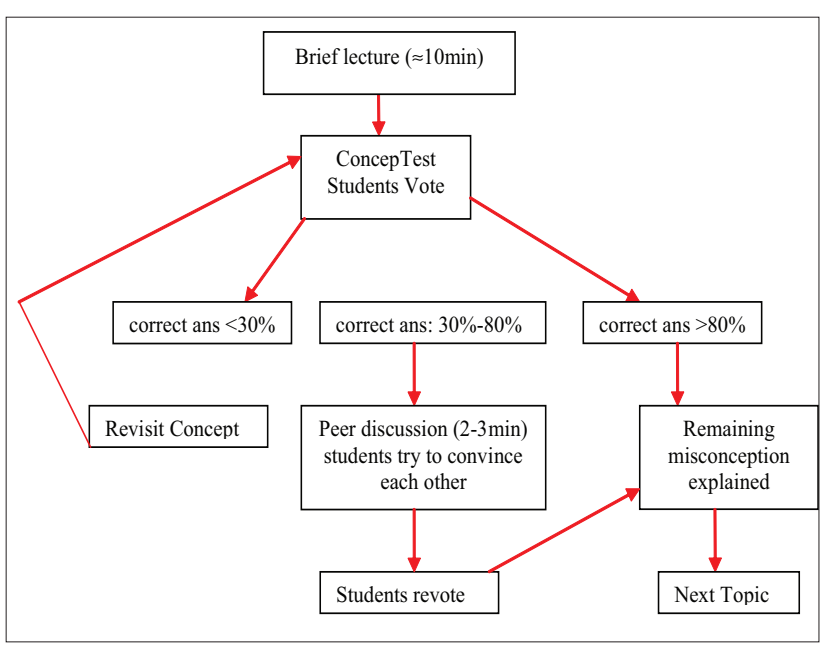

Fig. 1. A Peer Instruction Implementation Algorithm.

cepTests: multiple-choice conceptual questions. In the early 1990s, students displayed their answer to ConcepTests using a show of hands and later flashcards. Instructors would then count or estimate the number of students holding each alternative conception. Due to the tediousness of counting flashcards in large enrolment courses, flashcards were replaced with wired classroom communication systems $s^{3}$ and later with wireless clickers.

\section{Study Description}

First-semester students in a two-year Canadian public community college were randomly assigned by the registrar to one of two sections of an algebra-based mechanics course. Instruction in the first section consisted of PI with clickers $(n=41)$ while the other 
followed PI with flashcards $(n=42)$ to respond to inclass ConcepTests. Both sections were taught by the author, followed the same course structure and content (using 3-4 ConcepTests with peer discussion in each class), and had the same laboratory component.

Conceptual understanding was measured in both groups during the first and last week of the semester with the Force Concept Inventory. ${ }^{5}$ Also assessed were students' final exam scores on the college's very traditional final examination. This exam was constructed by a committee of physics instructors (none of whom were involved with this study) and had to be approved unanimously by all those teaching the course (10-12 instructors). Note that the other 10 groups of this cohort did not use PI, and a comparison with these groups will be the topic of a separate paper. Each instructor marked a single exam question for the entire cohort $(n \approx 500$; not just for his or her students $n \approx$ 40 ). This insured that no group had an exam of a differing difficulty or a corrector of different generosity. Furthermore, the correctors of the exam questions were unaware of which students belonged to which treatment condition.

\section{Results: Comparing Clickers to Flashcards}

To determine the difference in learning between clickers and flashcards, the FCI pre-test, FCI posttest, FCI normalized gain, ${ }^{6}$ and exam data are compared for both PI groups below:

Table I. The effect of clickers: difference in learning data between flashcard and clicker groups.

\begin{tabular}{|l|c|c|c|c|}
\hline & $\begin{array}{c}\text { Pre-FCl } \\
130\end{array}$ & $\begin{array}{c}\text { Post-FCl } \\
130\end{array}$ & $g$ & $\begin{array}{c}\text { Exam } \\
(\%)\end{array}$ \\
\hline $\begin{array}{l}\text { Clickers } \\
(n=35)\end{array}$ & $\mathbf{1 1 . 9}$ & $\mathbf{1 9 . 9}$ & $\mathbf{0 . 4 8 6}$ & 69.8 \\
\hline $\begin{array}{l}\text { Flashcards } \\
(n=34)\end{array}$ & $\mathbf{1 3 . 6}$ & $\mathbf{2 1 . 3}$ & $\mathbf{0 . 5 2 0}$ & 71.6 \\
\hline $\begin{array}{c}t \text {-test } \\
(2 \text {-tailed) } p\end{array}$ & 0.209 & 0.351 & 0.745 & 0.630 \\
\hline
\end{tabular}

Both groups do not differ significantly in FCI score at the beginning of the semester $(p=0.209)$ or at its end (0.351). These results show that the use of clickers does not add to the amount of conceptual learning or to exam performance. Indeed, although clickers have been reported to have a motivating influence, over the course of a semester no significant differences were found in conceptual learning gains $(p=0.745)$ nor in traditional examinations (0.630). This implies that PI is an effective instructional approach that is independent of the use of technology such as clickers.

\section{Lack of Difference in Learning}

These data show that clickers do not provide any additional learning benefit to students. Previous users of clickers in university classrooms have reported benefits such as increased rates of attendance and decreased rates of attrition. ${ }^{4}$ However, no data were found in this study to support the claim that clickers increase conceptual learning or exam performance. $\mathrm{PI}$ is a pedagogical approach that emphasizes basic concepts, has students commit to a conception, provides a setting for peer discussion, and has instructors explicitly address misconceptions. The technology by itself is not the pedagogy. But if clickers don't add to learning, what is their contribution?

\section{Description of Teaching Differences}

The contribution of clickers is more on the teaching side than on the learning side of the educational equation. For instance, whereas flashcards require taking class time to tabulate responses or estimate answer distributions, clickers allow instructors to automatically get precise real-time student feedback. A few other differences can be identified between clickers and flashcards such as: the ability to archive student responses, the appeal of technology, and institutional expense.

\section{Archiving Student Response Data}

Using clickers also allows instructors to archive all the data relative to students' answers of in-class ConcepTests. Beyond data analyses and research questions that can be later addressed, these data can be used instructionally to sort out useful ConcepTests from those that work poorly. Furthermore, ConcepTests of questionable effectiveness could be reformulated and a core set of questions can evolve from one semester to another. Flashcards do not enable the instructor to automatically archive any Concep Test-related data. Thus, reusing the same flashcard questions from 
semester to semester may differ in effectiveness from using clicker questions that have been modified from one semester to the next.

\section{The Appeal of Technology}

Clickers have contributed to the spread of the PI approach. ${ }^{7}$ Many instructors, including myself, have adopted the PI approach due to the appeal of using this technology in their classrooms. Using PI with clickers, however, forces instructors to reconsider their teaching, focus on concepts, and thus fundamentally reshape their instruction. Therefore, the presumption that using clickers is more effective turns out to be true if one moves from traditional instruction to PI with clickers.

\section{Institutional Expense}

Some instructors may be aware of PI methodology and willing to reshape their instruction to provide greater focus on basic concepts. Yet, the capital expense for the purchase of clickers and related hardware may not be available, and passing the expense on to the students may not possible or desirable. As PI is effective regardless of the method used to obtain feedback from students, in this instance PI should be implemented with flashcards.

\section{Conclusion}

Clickers are usually used in the classroom to enhance teaching and learning. From a teaching perspective, clickers have a number of very practical advantages: they allow instructors to get precise real-time feedback and store students' responses to ConcepTests. Furthermore, using clickers draws attention to $\mathrm{PI}$ and requires instructors to shift their focus toward conceptual instruction. From a learning perspective, using PI with clickers does not provide any significant learning advantage over low-tech flashcards. PI is an approach that engages students and challenges them to commit to a point of view that they can defend.

The pedagogy is not the technology by itself.

\section{Acknowledgment}

The author is grateful to Eric Mazur and Jessica Watkins for valuable comments and discussions on the manuscript. This study was supported by the Programme d'Aide sur la Recherche en
Enseignement et en Apprentissage (PAREA) of the Ministère de l'Éducation du Québec.

\section{References}

1. Eric Mazur, Peer Instruction: A User's Manual (Prentice Hall, Upper Saddle River, NJ, 1997).

2. C.H. Crouch and E. Mazur, "Peer Instruction: Ten years of experience and results," Am. J. Phys. 69, 970-977 (Sept. 2001); A. Fagen, C.H. Crouch, and E. Mazur, "Peer Instruction: Results from a range of classrooms," Phys. Teach. 40, 206-209 (April 2002).

3. A.L. Abrahamson, presented at the International Conference of the Teaching of Mathematics, Village of Pythagorean, Samos, Greece, 1998 (unpublished); A.L. Abrahamson, presented at the International Workshop, New Trends in Physics Teaching, Puebla, Mexico, 1999 (unpublished).

4. R.E. Lopez-Herrejon and M. Schulman, presented at the 9th Annual SIGCSE Conference on Innovation and Technology in Computer Science Education, 2004 (unpublished); K. Owens, D.A. McConnell, D. Steer, S. Van Horn et al., presented at The Geological Society of America Annual Meeting, Denver, 2004 (unpublished).

5. I.A. Halloun, R.R. Hake, E.P. Mosca, and D. Hestenes, in Peer Instruction: A User's Manual, edited by Eric Mazur (Prentice Hall, Upper Saddle River, NJ, 1995); D. Hestenes, M. Wells, and G. Swackhamer, "Force concept inventory," Phys. Teach. 30, 141-158 (March 1992).

6. R.R. Hake, "Interactive-engagement versus traditional methods: A six-thousand-student survey of mechanics test data for introductory physics courses," Am. J. Phys. 66, 64-74 (Jan. 1998).

7. R.A. Burnstein and L.M. Lederman, "Using wireless keypads in lecture classes," Phys. Teach. 39, 8-11 (Jan. 2001); R.A. Burnstein and L.M. Lederman, "Comparison of different commercial wireless keypad systems," Phys. Teach. 41, 272-275 (May 2003).

PACS codes: 01.40.gb, 01.55.+b 